\title{
Don't stop believing: Rituals improve performance by decreasing anxiety
}

\author{
Alison Wood Brooks ${ }^{a, *, 1}$, Juliana Schroeder ${ }^{b, 1}$, Jane L. Risen ${ }^{c}$, Francesca Gino ${ }^{a}$, Adam D. Galinsky ${ }^{\mathrm{d}}$, \\ Michael I. Norton ${ }^{a}$, Maurice E. Schweitzer ${ }^{e}$
}

\author{
${ }^{a}$ Harvard Business School, Harvard University, United States \\ ${ }^{\mathrm{b}}$ University of California, Berkeley, United States \\ ${ }^{\mathrm{C}}$ University of Chicago, United States \\ ${ }^{\mathrm{d}}$ Columbia University, United States \\ ${ }^{\mathrm{e}}$ Wharton School, University of Pennsylvania, United States
}

\section{A R T I C L E I N F O}

\section{Article history:}

Received 8 June 2015

Revised 5 July 2016

Accepted 18 July 2016

Keywords:

Ritual

Anxiety

Emotion regulation

Performance

\begin{abstract}
A B S T R A C T
From public speaking to first dates, people frequently experience performance anxiety. And when experienced immediately before or during performance, anxiety harms performance. Across a series of experiments, we explore the efficacy of a common strategy that people employ to cope with performance-induced anxiety: rituals. We define a ritual as a predefined sequence of symbolic actions often characterized by formality and repetition that lacks direct instrumental purpose. Using different instantiations of rituals and measures of anxiety (both physiological and self-report), we find that enacting rituals improves performance in public and private performance domains by decreasing anxiety. Belief that a specific series of behaviors constitute a ritual is a critical ingredient to reduce anxiety and improve performance: engaging in behaviors described as a "ritual" improved performance more than engaging in the same behaviors described as "random behaviors."
\end{abstract}

(c) 2016 Elsevier Inc. All rights reserved.

\section{Introduction}

From speaking in public to interviewing for a job to going on a first date, people frequently experience performance anxiety. Although anxiety can motivate beneficial preparation in the days or weeks before a performance, anxiety felt immediately before or during a performance typically harms performance (Eysenck, 1997; Lazarus, 1993). As a result, people engage in a wide range of strategies in an effort to diminish their anxiety - or at least prevent anxiety from undermining their performance.

The current research investigates the efficacy of a commonlyemployed coping strategy that people use to curtail preperformance anxiety: rituals. Ritual use is widespread, including by some of the most successful athletes and performers. For example, before every show, singer Beyoncé Knowles listens to the same playlist of songs, says a prayer with every member of her band, completes a specific set of stretches, sits in a massage chair while she has her hair and makeup done, and spends exactly one hour meditating. Wade Boggs, former third baseman for the Boston Red Sox, ate chicken before each game and wrote the Hebrew word

\footnotetext{
* Corresponding author.

E-mail address: awbrooks@hbs.edu (A.W. Brooks).

1 The first two authors contributed equally.
}

Chai ("life") in the dirt every time he went to bat. Tennis star Serena Williams bounces the ball exactly five times before her first serve and two times before her second serve. Ballerina Suzanne Farrell pinned a small toy mouse inside her leotard, crossed herself exactly twice, and pinched herself exactly twice before going on stage.

Despite the pervasiveness of pre-performance rituals, surprisingly little research has investigated whether or not rituals actually influence subsequent performance, and, if so, through what psychological mechanism. We suggest that rituals improve performance by reducing anxiety. Compared with other strategies intended to reduce anxiety, which either have limited empirical evidence to support their efficacy or can be difficult to implement, rituals may be particularly useful because they are relatively easy to implement and align with conventional wisdom - many people use them naturally to cope with their anxiety.

\section{Rituals, anxiety, and performance}

The study of rituals has a rich history in the anthropological, sociological, and psychological literatures, with a particular focus on the interpersonal effects of rituals. Previous research has identified both functional and dysfunctional consequences of group rituals (e.g., Atran \& Henrich, 2010; Blake, 2014; Collins, 
2004; Durkheim, 1912; Irons, 1996; Norenzayan \& Shariff, 2008; Rossano, 2012). In contrast, we focus on the possible intrapsychic benefits of rituals for individuals, predicting that rituals can reduce anxiety for individuals about to face a performance task. We develop this prediction by drawing on three literatures which demonstrate that: (a) rituals emerge when people experience anxiety, (b) pre-performance sports routines are used to boost performance, and (c) rituals that are connected to a broader belief system (like religious rituals) reduce anxiety for those who subscribe to the belief system.

First, prior research suggests that the occurrence of anxious feelings and rituals are correlated: ritualistic behavior emerges under circumstances characterized by high anxiety. One early description of the link between anxiety and rituals is Malinowski's (1954) observation of fishing behaviors among the Trobriand Islanders in Melanesia in the early 1900s. Malinowski noticed that the islanders performed elaborate rituals when traveling in unpredictable and dangerous ocean conditions but not when traveling in shallow, calm waters, and concluded that the islanders used rituals as a way to reduce the tension associated with uncertainty and with the unknown. Indeed, across cultures and throughout history, rituals have often accompanied stressful transitions, such as deaths, births, weddings, and graduations, as well as stressful performance situations such as public speaking and sports (Celsi, Rose, \& Leigh, 1993; Cohn, Rotella, \& Lloyd, 1990; Kirschenbaum, Ordman, Tomarken, \& Holtzbauer, 1982; Lobmeyer \& Wasserman, 1986; Moore, 1986; Norton \& Gino, 2014; Orlick, 1986; Wrisberg \& Pein, 1992). For example, Lang, Krátký, Shaver, Jerotijević, and Xygalatas (2015) used motion-capture technology to quantify speakers' hand movements when asked to speak in public, finding that feelings of anxiety increased the repetitiveness and rigidity of hand movements - which are considered signs of ritualistic behavior. Indeed, some scholars have even suggested that rituals develop from the experience of anxiety or uncertainty (Felson \& Gmelch, 1979; Lang et al., 2015; Singer \& Benassi, 1981; Vyse, 1997).

Similar behaviors emerge among people with clinical disorders involving anxiety, stress, or trauma. People suffering from these disorders often develop rituals as a coping mechanism (Rachman \& Hodgson, 1980). For example, individuals with obsessivecompulsive disorder are more likely to engage in ritualistic behaviors such as elaborate and repetitive sequences of finger tapping (Reuven-Magril, Dar, \& Liberman, 2008). Abuse victims (Jacobs, 1989) and palliative care patients (Romanoff \& Thompson, 2006) under intense stress also adopt rituals to cope with their conditions.

This foundational research provides correlational evidence that the type of people who engage in high-anxiety or high-uncertainty tasks may also be the type of people most likely to develop rituals, that moments of high anxiety increase the performance of rituals, and that people high in trait anxiety are likely to enact rituals. This research has conceptualized rituals as a product of anxious feelings but has not considered how enacting rituals might reduce anxiety. In contrast, the present research focuses on exploring the causal role of rituals in reducing state anxiety, a discrete emotion that affects a broader swath of people. Most people experience some level of state anxiety every day (Brooks \& Schweitzer, 2011). Such state anxiety is frequently triggered by social interactions, change, performance evaluations, and uncertainty (Gino, Brooks, \& Schweitzer, 2012; Gray, 1991). Our research extends prior research by assessing whether completing a ritual can causally reduce preperformance anxiety and thereby enhance task performance.

The second line of research underlying our predictions explores correlations between "pre-performance routines" intentionally learned by athletes and their subsequent performance (Foster, Weigand, \& Baines, 2006). Pre-performance routines often involve ritualistic elements including symbolism, repetitiveness, and rigidity (Dunleavy \& Miracle, 1979; Womack, 1992), such as eating exactly the same foods in the same order before a game or warming up for the game using a particular set of steps. Several studies suggest that pre-performance routines are correlated, at least directionally, with improved performance in basketball and golf (Cohn, 1990; Cohn et al., 1990; Gayton, Cielinski, FrancisKeniston, \& Hearns, 1989; Lobmeyer \& Wasserman, 1986; Predebon \& Docker, 1992; but see McCann, Lavallee, \& Lavallee, 2001). For example, basketball players who use pre-shot routines when making free-throw attempts, such as spinning the ball three times and bouncing it once before shooting it, tend to have a higher percentage of successful free-throws than those who do not (Czech, Ploszay, \& Burke, 2004). Furthermore, elite basketball athletes, who have higher stakes and perhaps higher anxiety when they play, tend to have more elaborate and longer pre-shot routines than do novice athletes (Wrisberg \& Pein, 1992).

Although these studies link pre-performance routines (involving ritualistic elements) with performance, they leave many questions unanswered including whether rituals can causally improve performance, and through what mechanism rituals might prove beneficial. First, the majority of these studies are correlational, use very small sample sizes (often fewer than ten participants), and do not include tests of statistical significance. Second, even if pre-performance routines consistently improve performance, it is unclear why. Pre-performance routines may reduce anxiety, but they also may be effective for other reasons, such as improving concentration (Cohn et al., 1990) or creating physical readiness (Foster et al., 2006). Finally, many pre-performance routines are purely functional and lack key ritualistic elements such as symbolism and rigidity. We address these open questions by using experiments with adequate statistical power and random assignment to explore the causal relationship between rituals and performance and assess the mediating role of anxiety.

A third line of relevant research examines the psychological consequences of deeply-ingrained cultural or personal rites including religious rites. People who engage in religious rites such as attending church or reciting the Rosary tend to feel less anxiety and recover faster from grief than those who do not (Ahler \& Tamney, 1964). Catholic college students assigned to recite the Rosary experienced a greater reduction in anxiety after a highanxiety experience than those assigned to watch a religious video (Anastasi \& Newberg, 2008); this research recruited participants with existing Catholic beliefs, and benefits were observed only among those with deeply-ingrained beliefs. Our research extends these results by examining whether implementing a novel ritual - which has never before been used by participants - can reduce anxiety and improve performance.

Finally, a recent set of experiments tested whether engaging in a novel ritual could alleviate grief for individuals who had experienced a loss (Norton \& Gino, 2014). These experiments revealed that participants who engaged in a novel ritual felt less grief than those who did not, regardless of their previous use of rituals or their belief in the efficacy of rituals. Here, we build on this research by assessing the effect of performing a novel ritual when people are in a high-arousal emotional state (anxiety), rather than a low-arousal state (sadness). Whereas Norton and Gino (2014) document that performing rituals after experiencing grief enhances perceived control and decreases grief, we predict that performing rituals prior to a high-anxiety performance can reduce anxiety and improve performance. In addition, Norton and Gino (2014) examined the effect of rituals when people lack control (i.e., the death of a loved one); in the current paper we study the effect of ritual when people are facing a situation in which they are in control of their outcomes (i.e., performance). 


\section{Defining ritual}

Across literatures in anthropology, religion, sports, ethology, sociology, and psychology, definitions of "ritual" vary widely, leading scholars to suggest that "there is no clear criterion by which cultural anthropologists or other scholars of religion or classics determine that a particular type of behavior is or is not an instance of a ritual" (Lienard \& Boyer, 2006, p. 814). In support of this assertion, Bell (1997) noted, "At one time or another, almost every human activity has been done ritually or made part of a ritual" (p. 91). Despite this lack of consensus among scholars, Legare and Souza (2012) show that laypeople often agree that rituals involve specific actions, multiple steps, repetition, and frequently involve symbolic elements such as religious icons.

Integrating theoretical and empirical conceptualizations of rituals, we identify three key criteria for rituals: a fixed sequence of behaviors, symbolic meaning, and non-functional behavior. First, rituals involve a fixed sequence of behaviors that are often characterized by formality and repetition. For example, Tambiah (1979) defined rituals as "patterned and ordered sequences of words and acts... characterized by conventionality, rigidity, fusion, and repetition" (p. 119). Similarly, Rossano (2012: 4) characterized rituals as "formalized, repetitious, attention-grabbing, rulegoverned actions" (Rossano, 2012, p. 4). Legare and Souza (2012) empirically showed that people's lay theories regarding the effectiveness of rituals depend on their number of steps and repetition of procedures.

A second key aspect of rituals is symbolic meaning: ritual enactors believe that ritualized behaviors have subjective meaning beyond their mere actions. Although some ritualized behaviors have been observed in animals (Rossano, 2012; Tinbergen, 1952), rituals are predominantly a human phenomenon, containing symbolism, sacredness, and traditionalism (Bell, 1997). In short, rituals may differ from other sequences of acts for the principal reason that they have "expressive or symbolic elements" (RadcliffeBrown, 1939, p. 143), and mean something to the people enacting them.

A third unique feature of rituals is that the actions that compose rituals typically lack overt instrumental purpose. The most recent psychological conceptualizations of rituals have contrasted them with routine actions, such as habits, that are practical or instrumental (e.g., Norton \& Gino, 2014; Ouellette \& Wood, 1998). In contrast, ritualized actions include non-functional behaviors that are not causally linked to the stated goal of the ritual (Boyer \& Liénard, 2006; Legare \& Souza, 2012; Lienard \& Boyer, 2006; Rappaport, 1999). This distinction between behaviors that are instrumental and goal-directed (e.g., routines) from those that include non-instrumental elements (e.g., rituals) are critical for understanding the difference between pre-performance rituals and mere pre-performance routines. For instance, a warm-up routine is conducted with a specific purpose or goal in mind and each step in the routine is functionally linked to preparing an athlete to perform at their best (e.g., stretching muscles to improve flexibility); in contrast, a warm-up ritual may involve some of same steps with the same goal, but is composed of steps that are not logically necessary for preparation - such as bouncing a basketball exactly three times or conducting certain steps in a particular fixed sequence. For this reason, we propose that to be considered a ritual, at least some - though not necessarily all - of the constituent behaviors must be non-instrumental.

In sum, we define ritual as a predefined sequence of symbolic actions often characterized by formality and repetition that lacks direct instrumental purpose. Across our experiments, we operationalize rituals using this definition, ensuring that each ritual we utilize contains these constituent elements.
Importantly, this definition enables us to distinguish between sets of actions that constitute a ritual and sets of actions that do not. In particular, a set of actions characterized as random behaviors can become a ritual when those actions are imbued with symbolic meaning. For instance, if someone performed a rain dance, they might interpret each behavior (e.g., pointing upwards) to have some symbolism (e.g., gesturing toward the sky to beckon rain). But if another person performed the same steps without knowing they were constituent elements of a rain dance, the steps would lack meaning and pointing upwards would be understood as merely pointing one's fingers. As a result, and given the wide range of behaviors associated with the countless rituals documented in the previous literature, we expect that the specific steps included in the ritual do not matter as much for reducing anxiety as do performers' belief that those steps constitute a ritual.

\section{Rituals reduce anxiety}

Given their ubiquity in countless performance domains, it is possible and even likely that rituals may improve performance through several mechanisms. For example, rituals may prove helpful because they delay performance for a beneficial period of time, improve concentration, increase perceived control, or boost motivation. We focus on one mechanism that has previously been tightly linked to performance, assessing whether rituals improve performance by directly reducing anxiety.

Anxiety can both help and harm performance. If experienced far enough in advance of a performance event, anxiety can boost effort and preparation (e.g., Norem \& Chang, 2002). However, anxiety experienced immediately before or during a performance event often harms performance. For example, stereotype threat can induce anxiety that impedes performance (Schmader, Johns, \& Forbes, 2008). As a discrete emotion, anxiety is characterized by high arousal, negative valence, a sense of uncertainty, and a low sense of control, and is theoretically distinct from other emotions such as sadness and grief, which are characterized by low arousal (Gray, 1991; Raghunathan \& Pham, 1999; Smith \& Ellsworth, 1985). Anxiety drains working memory and impairs information processing: anxious individuals utilize working memory on processes such as worrying and ruminating instead of focusing on the task at hand (Eysenck, 1992), and feelings of anxiety increase egocentrism and impair the ability to take another person's perspective (Todd, Forstmann, Burgmer, Brooks, \& Galinsky, 2015).

Anxiety also negatively influences motivational mechanisms such as risk seeking and self-confidence (Han, Lerner, \& Keltner, 2007; Raghunathan \& Pham, 1999). Similarly, state anxiety has been shown to lower self-efficacy, the belief that one can succeed on a specific task (Bandura, 1997). Low self-efficacy, in turn, adversely affects decision-making and behavior. For example, negotiators who experience anxiety make low first offers, exit negotiations early, and earn less profit than neutral-state negotiators, effects that are mediated by negotiator self-efficacy (Brooks \& Schweitzer, 2011). Similarly, individuals who experience anxiety seek out and rely more heavily on advice - even when the advice is of low quality - due to their lack of confidence in their own ability to make good judgments (Gino et al., 2012).

Given the demonstrated benefits of reduced anxiety, scholars and practitioners across disciplines have searched exhaustively for tools and strategies that can effectively reduce anxiety. A number of well-intentioned and intuitively promising strategies have been proven ineffective for reducing anxiety. For example, suppressing anxiety - hiding anxious feelings from others - can paradoxically increase anxious feelings (Brooks, 2014; Gross \& Levenson, 1995). Other strategies lack rigorous experimental support or prove effective only under limited circumstances. For 
instance, there is only suggestive evidence of the efficacy of mindfulness meditation (Brunyé et al., 2013; Williams, Delizonna, \& Langer, 2009; Shearer, Hunt, Chowdhury, \& Nicol, 2015), distraction (Blagden \& Craske, 1996), alcohol consumption (Steele \& Josephs, 1988), and listening to music (Knight \& Rickard, 2001).

Research converges to suggest that two strategies can effectively reduce anxious arousal: expressive writing (Pennebaker, 1997; Ramirez \& Beilock, 2011) and emotional reappraisal (Crum, Salovey, \& Achor, 2013; Gross, 2002; Hofmann, Heering, Sawyer, \& Asnaani, 2009; Jamieson, Mendes, Blackstock, \& Schmader, 2010). For instance, one of the most pervasive clinical techniques for reducing anxiety is cognitive behavioral therapy, based on principles of reappraisal (Webb, Miles, \& Sheeran, 2012). However, reappraisal can be difficult to implement, especially for highmagnitude emotions (Shafir, Schwartz, Blechert, \& Sheppes, 2015), and may be most effective not for reducing high-arousal emotions (such as anxiety), but for reframing negatively-valenced high arousal as positively-valenced high arousal (such as reappraising anxiety as excitement; Brooks, 2014).

We propose a novel strategy to reduce anxious arousal: enacting rituals. A series of experiments examine the efficacy of rituals for reducing pre-performance anxiety, and the consequences of that anxiety reduction on performance. Rituals may be a particularly promising avenue for anxiety reduction because they are both easy to implement and align with conventional wisdom - many people use rituals naturally to cope with their anxiety.

Why do rituals reduce anxiety? We suggest that there are at least four possible reasons. First, performing the rigid, repetitive actions of a ritual may satisfy a fundamental need for order. Boyer and Liénard (2006) theorized that ritualized actions are an evolutionary vestige of a vigilance detection system. Consistent with this, the entropy model of uncertainty posits that anxiety motivates organisms to return to familiar low-entropy states in order to regain a sense of control (Hirsch, Mar, \& Peterson, 2012; Lang et al., 2015). A second possibility is that rituals could serve as a potent form of distraction, blocking negative thoughts from entering a person's mind. In line with this reasoning, Boyer and Liénard (2008) further proposed that the low-level action units of completing rituals can swamp working memory. This attentional demand could minimize anxiety by blocking intrusive thoughts (Van Dillen \& Koole, 2007).

A third possibility is that the symbolic value of a ritual may provide a buffer against threat and anxiety; for example, religious rituals provide a sense of meaning that transcends the self (Anastasi \& Newberg, 2008). We propose that even secular rituals may provide a sense of meaning and perspective, allowing people to expand their working self-concept beyond the threatened domain (e.g., Critcher \& Dunning, 2014). Finally, a fourth possibility is that rituals function as a type of placebo (e.g., Crum \& Langer, 2007). That is, if an individual believes there is a chance a ritual may help him perform better, then his anxiety about the performance will actually decrease, and this decrease in anxiety, in turn, will improve performance. The third and fourth explanations suggest that performing the steps of a ritual alone may not be enough to reduce anxiety: we therefore test whether people must believe that they are enacting a ritual in order for a series of steps to effectively reduce anxiety and improve performance.

\section{Empirical overview and theoretical contributions}

We conducted a series of studies to test our prediction that rituals improve performance by reducing anxiety. We use both mediation and moderation to document the underlying processes (Spencer, Zanna, \& Fong, 2005). In a Pilot Study, we investigate the types of rituals people naturally use prior to performing anxiety-inducing tasks. In Studies $1 \mathrm{a}$ and $\mathrm{b}$, we test whether engaging in a ritual influences pre-performance anxiety (assessed via both self-reported and physiological measures) and performance in a domain that frequently induces anxiety: singing in public. In Study 2, we extend our investigation using a private anxiety-inducing performance task: a math test. In Studies 3-4, we compare the efficacy of enacting a set of behaviors described as a "ritual" or the same set of behaviors described as "random behaviors." We predicted that participants' belief that a series of steps constitute a ritual is critical for reducing anxiety and improving performance.

Our research makes several theoretical contributions. First, we add to the emerging literature documenting the causal impact of rituals on psychological outcomes (e.g., Norton \& Gino, 2014; Vohs, Wang, Gino, \& Norton, 2013; Zhang, Risen, \& Hosey, 2014). We use experimental methodology to demonstrate the causal effect of enacting rituals on reducing anxiety and enhancing performance; existing research has typically relied on qualitative designs, precluding causal inferences about the effects of rituals (Rossano, 2012). Second, whereas earlier studies have focused on how uncertainty or anxiety can prompt ritualistic behavior (Whitson \& Galinsky, 2008), we test the reverse causal pathway: that completing a ritual can influence the experience of anxiety. Third, whereas clinical psychological research examines the relationship between trait anxiety and rituals (Rachman \& Hodgson, 1980), we extend this literature by testing the effect of performing a ritual on state anxiety. Fourth, we utilize novel rituals that do not have functional value or deeply-ingrained cultural significance, allowing us to differentiate rituals from related constructs such as habits or pre-performance routines (which may create physical readiness), and superstitions (which have an effect only if performers believe in luck; Damisch, Stoberock, \& Mussweiler, 2010). Finally, whereas prior research focuses on the notion that rituals serve primarily social functions (Collins, 2004; Durkheim, 1912), we suggest that rituals operate at the intrapsychic level and prove beneficial even when performed alone.

On a practical level, our results contribute to the literature on anxiety management. As noted above, research on emotion regulation demonstrates that suppressing anxiety is both difficult and can paradoxically increase anxious feelings (e.g., Brooks, 2014; Gross \& Levenson, 1995). In contrast, we propose and demonstrate that rituals offer a strategy that effectively decreases pre-performance anxiety. Critically, we compare the effectiveness of rituals to other strategies - such as trying to calm down, or delaying a task - to show that rituals exert a unique influence on anxiety, which in turn psychologically drives the effect of rituals on performance.

\section{Pilot study: Exploring pre-performance rituals}

We conducted a pilot study to investigate the types of rituals people use prior to anxiety-inducing performance tasks. The pilot study was designed to gather qualitative evidence in support of our definition of ritual - a predefined sequence of symbolic actions characterized by formality and repetition that lacks direct instrumental purpose - in the rituals reported by laypeople. We expected that people's real-life rituals would contain symbolic connection to the upcoming task, and would be distinct from superstitions or religious rites. In addition, assessing the features of people's real pre-performance rituals served as a critical input in helping us to create and situate our experimental instantiations of ritual.

We predetermined a sample size that we believed would provide enough data to capture different elements of rituals, recruiting 400 participants $\left(M_{\text {age }}=31.70, S D=9.09 ; 58 \%\right.$ male $)$ on Amazon's 
Table 1

Coding of participants' responses about their own rituals (Pilot Study). Participants reported whether or not their rituals involved each of the following elements.

\begin{tabular}{|c|c|c|c|c|}
\hline & $\begin{array}{l}0=\text { Not listed (participants did } \\
\text { not specify) }\end{array}$ & 1 & 2 & 3 \\
\hline Performed alone [1] or with others [2]? & $13 \%$ & $84 \%$ & $3 \%$ & \\
\hline Ritual was new to the individual [1] or had been performed before [2]? & $13 \%$ & $16 \%$ & $71 \%$ & \\
\hline $\begin{array}{l}\text { Did the person invent this ritual [1], did they follow an existing custom such as knocking on wood [2], or did } \\
\text { they adapt an existing custom [3]? }\end{array}$ & $13 \%$ & $31 \%$ & $35 \%$ & $21 \%$ \\
\hline The ritual was connected [1] or unconnected [2] to the subsequent task? & $14 \%$ & $76 \%$ & $10 \%$ & \\
\hline Did the person explicitly mention trying to calm down/relax/get excited/psyched up [1] or imply it [2]? & $15 \%$ & $30 \%$ & $56 \%$ & \\
\hline Number of steps in the ritual: one step [0], two steps [1], three steps [2], more than three steps [3]? & $16 \%$ & $43 \%$ & $21 \%$ & $20 \%$ \\
\hline Involved religious element(s) [1] or not [2]? & $14 \%$ & $17 \%$ & $69 \%$ & \\
\hline Involved superstitious element(s)? (e.g., knocking on wood, throwing salt, crossing fingers) [1] if yes, [2] if no & $14 \%$ & $20 \%$ & $66 \%$ & \\
\hline Involved lucky/special item(s)? (e.g., rabbit's foot, lucky underwear) [1] if yes, [2] if no & $14 \%$ & $15 \%$ & $72 \%$ & \\
\hline Involved physical activity [1], cognitive activity [2], or both physical and cognitive activity [3]? & $14 \%$ & $11 \%$ & $27 \%$ & $48 \%$ \\
\hline
\end{tabular}

Mechanical Turk to complete a study in exchange for $\$ 0.50$ each. We presented respondents with only the two following questions:

(1) Think about a time when you faced a difficult task and you felt anxious about it (e.g., a test, a sport competition, an interview). Did you engage in a ritual before performing the task? (YES/NO)

(2) Please describe the ritual you performed in detail. If you answered NO, please describe another ritualistic behavior you have performed in the past and when you performed it.

Nearly half of our participants (46.5\%) reported performing a ritual in a specific anxiety-inducing situation, suggesting that enacting rituals is a relatively common response to high-anxiety situations, consistent with prior research (Celsi et al., 1993). In line with our assertion that rituals may have benefits not just for people with trait anxiety but also in situations that provoke state anxiety, performing a ritual seems to be a strategy that many people use before high-anxiety performances.

We asked two independent raters to read participants' openended responses and code them along a variety of dimensions. The two coders agreed $97 \%$ of the time; a third coder resolved disagreements. We summarize the information regarding the coding of the participants' responses in Table 1.

As Table 1 shows, most of the rituals were performed individually (84\%), supporting our assertion that rituals are not only social phenomena but also operate at the individual level. Thus, we had participants complete the ritual individually in our experiments.

Most rituals were not new to the individual (71\%), indicating that people tend to perform rituals more than once. Note, however, that even though they were repeated, rituals were often not composed of existing customs (35\%), but were instead invented by individuals (31\%) or adapted from customs (21\%); these qualitative results informed our decision to use novel rituals in our experiments.

Most rituals (76\%) included steps that were connected to the upcoming task, but not necessarily instrumental for improving performance in the task (e.g., putting on cleats and socks in the same way before each soccer game). The notion of connection between the ritual and the task is consistent with our theoretical definition of rituals as containing symbolic elements that imbue the ritual with meaning. In our studies, we create meaning in two different ways. First, we connect one of the steps of the ritual to feelings (Studies 1-2), and second, we emphasize the ritualistic meaning of the steps of the ritual by describing them as a "ritual" compared to describing them as "random behaviors" (Studies 3-4).

Finally, the Pilot Study revealed that, in general, people's rituals were often not spiritual (69\%) and often did not involve superstitious elements $(66 \%)$ or lucky items $(72 \%)$. Rituals tended to include both physical and cognitive elements (48\%). These data are consistent with our conceptualization of rituals as distinct from religious rites and superstitions. We therefore designed our instantiations of rituals to include both physical and cognitive elements, without overtly superstitious or religious elements.

\section{Study 1: Rituals and singing performance}

In Studies 1a and b, we investigate how rituals influence performance in an anxiety-inducing performance domain: singing in public. We randomly assigned participants to complete a ritual (or not) before singing “Don't Stop Believing” by Journey in front of strangers (see Brooks, 2014), and tracked their self-reported anxiety, heart rate, and objective singing quality. Our conceptual account holds that rituals are psychologically distinct from other common pre-performance strategies such as actively attempting to calm down or delaying performance for a period of time. Thus, we compare the effectiveness of rituals to waiting (Studies 1a and $1 \mathrm{~b}$ ) and trying to calm down (Study $1 \mathrm{~b}$ ), predicting that rituals would be more effective in reducing anxiety and improving performance.

\subsection{Study $1 a$}

In Study 1a, after asking participants to complete a ritual (or not) before singing publicly, we measured self-reported emotional experience and singing quality assessed by voice recognition software.

\subsubsection{Participants}

We predetermined a sample size of at least 40 participants per condition. This was the maximum sample size the lab would support and we were unsure of what effect size to expect. We recruited until the end of the final day, which yielded slightly more participants than our predetermined number. Specifically, we recruited eighty-five native English-speaking students $\left(M_{\text {age }}=20.26, S D=2.12,42 \%\right.$ male $)$ from a Northeastern university to participate in an experiment for pay. Participants received a $\$ 5$ show-up fee and could earn up to an additional $\$ 5$ based on their performance in the study.

\subsubsection{Design}

We randomly assigned participants to one of two experimental conditions: Ritual or No Ritual.

\subsubsection{Procedure}

We recruited participants to arrive every eight minutes for the duration of the study. Upon arrival, an experimenter kept participants in a waiting room where they completed an unrelated filler task. 
A second experimenter called participants into a second room one at a time, where they read instructions for the study. Participants read that they would be singing the song "Don't Stop Believin"' by Journey in front of an experimenter and that they would be paid based on their singing accuracy score (up to $\$ 5$ extra). We chose "Don't Stop Believin"' as the target song because it can be performed in three different octaves. Therefore, the song was suitable for both male and female participants. "Don't Stop Believin"” was also one of the most downloaded songs in iTunes history and, we thought, would be familiar to most English speakers. Participants listened to a one-minute clip of "Don't Stop Believin'."

7.1.3.1. Ritual manipulation. We randomly assigned them to one of two conditions: Ritual or No Ritual. In the Ritual condition, participants read the following instructions (adapted from Norton \& Gino, 2014), based on our ritual definition as a predefined sequence of symbolic actions characterized by formality and repetition that lacks direct instrumental purpose:

Please do the following ritual: Draw a picture of how you are feeling right now. Sprinkle salt on your drawing. Count up to five out loud. Crinkle up your paper. Throw your paper in the trash.

Participants had one minute to complete the ritual. In the No Ritual condition, we asked participants to sit quietly for one minute.

Next, a third experimenter, blind to experimental condition, accompanied the participant into a third room where a Nintendo Wii was set up with a microphone and a television screen. The experimenter handed the microphone to the participant and explained, "You will sing into this microphone. The lyrics will appear across the bottom of the screen." Then the participant sang "Don't Stop Believin"” using Konami's Karaoke Revolution program while the experimenter sat in front of him or her, watching.

7.1.3.2. Singing accuracy. At the end of the song, the karaoke program calculated an objective performance score using Konami's voice recognition software. The program terms its performance measure "singing accuracy," which was calculated on a $0-100 \%$ scale. According to information provided by Konami in May 2012, singing accuracy reflects an average of the software's measurement of volume (quiet-loud), pitch (distance from true pitch), and note duration (accuracy of breaks between notes). Singing accuracy score served as our main dependent measure.

7.1.3.3. Self-report measures. Participants finished the study in a separate computer lab where they completed other measures on a computer. In particular, we assessed their emotions and their demographics. After participants finished singing, we asked them to think back to how they felt before their performance and indicate the extent to which they felt each of seven emotions (see Brooks \& Schweitzer, 2011) on a seven-point scale ( $1=$ Not at all, 7 = Very much). Three items measured anxious feelings (anxious, tense, and nervous, $\alpha=0.86$ ); two items measured excitement (excited, enthusiastic, $\alpha=0.91$ ); and two items measured neutral feelings (neutral, unemotional, $\alpha=0.82$ ). We also included a song recognition check ( $I$ recognized the song, $1=$ Strongly disagree, 7 = Strongly agree) and demographics (age, gender). At the end of the study, an experimenter paid participants a bonus based on their singing accuracy score.

\subsubsection{Results}

7.1.4.1. Singing accuracy. We conducted an independent samples $t$ test with singing accuracy (score out of $100 \%$ ) as the dependent variable and ritual condition as the independent variable. Performing a ritual improved singing accuracy. Participants sang more accurately after doing a ritual $(M=78.47 \%, S D=13.89 \%)$ than they did after sitting quietly for a minute $(M=65.70 \%, S D=16.89 \%), t$ $(79)=4.05, p<0.001, d=0.83$. There were no effects of age, gender, or song recognition on singing performance ( $p s>0.19$ ), though, as expected, song recognition was very high on average $(M=6.47$ out of $7, S D=1.30$ ).

7.1.4.2. Self-reported emotions. We conducted separate $t$-tests with self-reported anxiety, excitement, and neutral feelings as dependent measures. We included ritual condition as the independent variable. On average, self-reported anxiety was high leading up to the singing task $(M=5.14$ out of $7, S D=1.64)$. Consistent with our predictions, we found a main effect of ritual condition on self-reported anxiety. Participants who completed a ritual before singing reported feeling significantly less anxious $(M=4.15$, $S D=1.37)$ than did participants who did not complete a ritual before singing $(M=5.94, S D=1.40), t(85)=5.89, \quad p<0.001$, $d=1.29$. There were no significant effects of age, gender, or song recognition on self-reported anxiety, all $p s>0.06$. We found no effects of ritual condition, gender, or age on excitement or neutral feelings leading up to the singing task, all $p s>0.25$.

7.1.4.3. Mediation. Self-reported anxiety mediated the effect of ritual condition on singing performance. A bootstrapping analysis with 5000 iterations (MacKinnon, Fairchild, \& Fritz, 2007) revealed a significant indirect effect: the 95\% bias-corrected confidence interval for the indirect effect did not include zero [0.12,0.24].

For robustness, we also tested the reverse causal model: did performance on the singing task mediate the relationship between ritual condition and anxiety? This is possible because participants reported the anxiety they felt leading up to the singing task (preperformance anxiety) at the end of the experiment. This causal pathway is unlikely, because although participants may have been loosely aware of the quality of their own singing performance as they sang, participants did not learn their objective singing accuracy score until after completing the self-report measure of anxiety. Consistent with this notion, singing performance did not mediate the effect of ritual condition on self-reported anxiety; the 95\% bias-corrected confidence interval for the indirect effect included zero $[-0.23,0.52]$, suggesting no indirect pathway in this order.

\subsubsection{Discussion}

Enacting a randomly-assigned novel ritual before an anxietyinducing performance task reduced self-reported anxiety and improved subsequent singing performance. Importantly, we found that rituals increased performance by reducing anxiety.

These findings support our account, but contain several limitations. First, anxiety was self-reported after the performance; in Study $1 \mathrm{~b}$, we use a real-time physiological measure of anxiety. Second, we compared performing a ritual to simply waiting, such that the two conditions varied on multiple dimensions. In Studies 3 and 4 , we carefully match ritual and non-ritual conditions on all features except for the description of "ritual."

\subsection{Study $1 b$}

In Study 1b, we extend these findings by measuring a physiological correlate of anxiety: heart rate. Anxiety is characterized by high arousal and an increased heart rate (e.g., Lang, Greenwald, Bradley, \& Hamm, 1993; Smith, Bradley, \& Lang, 2005), so in Study 1b we measured heart rate before and after performing a ritual. Though heart rate measures generalized arousal, not anxiety specifically, heart rate data provides valuable physiological information when paired with self-reported emotion data (e.g., as in Study 1a). In Study 1b, while monitoring participants' 
heart rates, we asked them to perform a pre-performance ritual (or not) and then sing in front of each other.

In addition, we added a third condition to the two-condition Study 1 a design, in which we instructed participants to use another common pre-performance strategy: actively trying to calm down. Consistent with our account, we expected to replicate Study 1a, and also to show that enacting a ritual is more effective at reducing anxiety than active attempts to calm down.

\subsubsection{Participants}

We increased our sample size from Study 1a and aimed for at least fifty participants in each experimental condition because we expected that there might be greater variance in the physiological measure and that the effect of ritual on heart rate might yield a smaller effect size than the effect of ritual on self-reported anxiety. Again, we committed to recruiting through the end of the final day, which yielded slightly more participants than our predetermined number. In total, we recruited 167 students from a Northeastern university $\left(M_{\mathrm{age}}=19.84\right.$ years, $S D=1.48,42 \%$ male) to participate in a lab study in exchange for a $\$ 5$ show-up fee.

\subsubsection{Design}

We randomly assigned participants to one of three experimental conditions at the group level: Ritual, Calm, or No Ritual.

\subsubsection{Procedure}

We recruited participants to a behavioral lab and seated them in separate cubicles. The smallest experimental session had six participants, and the largest experimental session had fourteen. An experimenter guided participants through the study. Because instructions were read aloud by the experimenter, we randomly assigned participants to experimental condition at the group level (varied across experimental sessions).

7.2.3.1. Heart rate measure. To measure participants' heart rate, we used a procedure from Brooks (2014). First, the experimenter instructed participants to place a wireless finger pulse oximeter (DigiO2 Finger Pulse Oximeter) on their non-dominant pointer finger and to rest the oximeter flat on the desk in front of them. Pulse oximeters provide very accurate measures of heart rate - in exercise studies, they correlate with ECG ratings at $r=0.91$ (Iyriboz, Powers, Morrow, Ayers, \& Landry, 1991). The experimenter told participants to close their eyes and breathe deeply for ten seconds. After ten seconds, participants recorded their own resting heart rate in beats per minute (PrBPM) by reading the screen of the oximeter and typing the value on the computer (this was the time 1 reading). Participants reported no difficulties reading the number from the screen.

Next, the experimenter announced that each participant would be singing the first verse of “Don't Stop Believing” by Journey in front of the group. Immediately after learning about the singing task, participants recorded their heart rate (time 2 reading).

After completing the experimental manipulation, participants recorded their heart rate (time 3 reading). For experimental control across all three conditions, the experimenter paused for exactly one minute between the end of the song instructions (time 2) and the end of the manipulation (time 3), even in the No Ritual condition. During this time, the experimenter simply asked participants to wait before singing.

7.2.3.2. Ritual manipulation. We randomly assigned participants to one of three experimental conditions: Ritual, Calm, or No Ritual. In the Ritual condition, participants completed the same ritual we used in Study 1a. In the Calm condition, the experimenter told participants: "Do your best to calm down before you sing." In the No
Ritual condition, participants did not receive additional instructions but were asked to wait patiently for a few moments.

7.2.3.3. Singing task. Next, participants gathered at the front of the room and took turns singing the opening phrase of "Don't Stop Believing" by Journey in front of each other:

Just a small town girl, living in a lonely world. She took the midnight train going anywhere. Just a city boy, born and raised in South Detroit. He took the midnight train going anywhere.

7.2.3.4. Self-report measures. Finally, participants returned to their cubicles and completed a short questionnaire on the computer that assessed their familiarity with the song and demographic questions including age and gender.

\subsubsection{Results}

Song recognition was high across all conditions $(M=6.38$ out of $7, S D=1.58$ ), and we found no effects of song recognition, age, gender, or experimental session (group) on heart rate ( $p s>0.20$ ). The pattern of results was the same with or without these control measures, and we present Study $1 \mathrm{~b}$ results collapsed across these variables.

We conducted a repeated-measures ANOVA with heart rate as the dependent measure and ritual condition as the independent variable. We controlled for participant-level fixed effects across time by running a repeated-measures ANOVA. There were three measurement times for each participant: baseline heart rate (time 1 ), after learning about the singing task (time 2 ), and after enacting a ritual, trying to calm down, or waiting patiently (time 3 ). Time 3 heart rate measurement occurred after the manipulation but before the singing task. Consistent with our hypotheses, we found a main effect of ritual condition on heart rate over time, $F(1,496)$ $=4.52, p=0.03$. $^{2}$

Collapsing across ritual condition, we found a significant increase in mean heart rate between time 1 (resting heart rate, $M=74.95$ PrBPM, $S D=7.97$ ) and time 2 (after finding out about the singing task, $M=80.34$ PrBPM, $S D=7.61$ ), paired $t(167)$ $=-6.31, p<0.001, d=0.69$. That is, our singing task instructions significantly increased arousal. We did not find a significant difference between heart rate at time 2 (after finding out about the singing task) and heart rate at time 3 (immediately before singing, $M=79.87, S D=7.13), p=0.56, d=0.06$. That is, on average, arousal remained high leading up to the singing task. However, time 3 heart rate was significantly lower after enacting a ritual $(M=77.37, S D=7.14)$ than after "waiting patiently" $(M=81.39$, $S D=5.09, t(110)=3.55, p<0.001, d=0.65)$ or "trying to calm down" $(M=80.58, S D=9.53, t(113)=2.09, \quad p=0.039, \quad d=0.38)$ (see Fig. 1). Time 3 heart rate did not differ significantly between the "wait patiently" and "calm down" conditions $(p=0.64)$. As expected using a repeated-measures design, there were also participant-level fixed effects across time $(F(1,496)=9.90$, $p=0.001$ ), indicating that heart rate was correlated within individuals across the three measurement times.

\subsubsection{Discussion}

In Study 1b, heart rate increased after learning about a singing task, but decreased only following a ritual; heart rate remained elevated when people either waited or tried to calm down. The results of this study suggest that performing a ritual decreases preperformance anxiety by diminishing arousal, a physiological

\footnotetext{
${ }^{2}$ We observe the same pattern of results whether we use raw heart rate values, as reported here, or by calculating the difference between current heart rate and resting heart rate.
} 


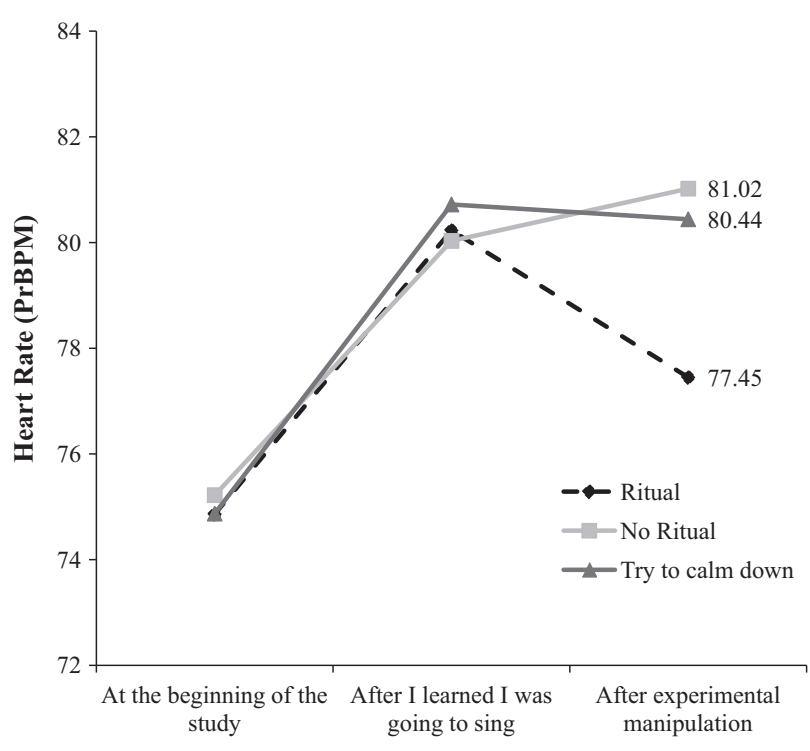

Three measurements across time

Fig. 1. Heart rate by experimental condition before singing (Study $1 \mathrm{~b}$ ). Only doing a ritual reduced heart rate.

correlate of anxiety. Performing a ritual was more effective at reducing heart rate than actively attempting to calm down.

\section{Study 2: Rituals and math performance}

We suggest that rituals improve performance by reducing anxiety. Study 1 offers support for this account via mediation. In Study 2 , we offer further support though moderation. If rituals exert an impact on performance primarily through mechanisms other than anxiety, then we would expect rituals to boost performance in situations where anxiety is both high and low. If, as we posit, a critical driver of the effect of rituals on performance is their specific effect on anxiety, then we would predict that rituals would affect performance only when anxiety is high and must be reduced in order to perform well. We compare the effects of rituals under conditions of high and low anxiety in Study 2.

We also use a different high-anxiety performance domain: math performance. Singing publicly may elicit both performance anxiety and social anxiety, whereas working on hard math problems under stressful conditions (e.g., time pressure) should elicit only performance anxiety, offering a clean test of our proposed ritual-performance anxiety link.

\subsection{Math task pilot study}

The math task used in Study 2 has been used in prior research (e.g., Brooks, 2014). To ensure that the task would induce anxiety and that anxiety would impair performance in our sample population, we conducted a pilot study with a non-overlapping sample as the main study. We predetermined our sample size to approximately double the sample sizes of prior research that used similar anxiety manipulations (e.g., Beilock, Kulp, Holt, \& Carr, 2004). In total, 187 individuals from Amazon's Mechanical Turk participated. We asked all participants to complete the same math task, but we manipulated the description of the task: Low Anxiety vs. High Anxiety.

In the Low Anxiety condition, participants read the following instructions:

"In this study, you will complete a series of eight fun math puzzles. You will earn $\$ .50$ for each question you answer correctly."
In the High Anxiety condition, participants read:

"In this study, you will complete a very difficult IQ test made up of eight questions under time pressure. For each question, you will have five seconds to select the correct answer. You and your peers will receive feedback about your accuracy after each question. If you answer every question correctly, you will earn $\$ 4$. For each question you answer incorrectly, you will lose fifty cents (\$.50)."

We wrote the High Anxiety instructions to maximize anxious arousal. Time pressure, loss framing, social evaluation, and the phrase "IQ test" have been shown to make people anxious (Beilock, 2008; Beilock \& Carr, 2005; Beilock et al., 2004; Brooks, 2014; Ramirez \& Beilock, 2011). After reading the task description (Low Anxiety or High Anxiety), participants completed the math task, a series of eight modular arithmetic math problems adapted from Mattarella-Micke, Mateo, Kozak, Foster, and Beilock (2011). Each question followed the same format using invented symbols. For example, "16 $\equiv 4 \bigcirc 3$ " meant " 16 minus 4 , divided by 3 ." If the solution was a whole number (e.g., 4), then the correct answer was "true." If the solution was not a whole number, then the correct answer was "false." Participants read instructions about the format of the math questions and completed one practice question online. Participants had five seconds to answer "true" or "false" before the task progressed. After each question, participants received online feedback about the accuracy of their previous answer, with the next computer screen displaying the correct answer.

After the task ended, participants answered questions about their subjective experience of pre-performance anxiety $(\alpha=0.69)$ with the same measure used in Study 1. Participants also answered demographic questions about their age and gender and were paid based on their math performance.

Consistent with our predictions, we found a main effect of experimental condition on the experience of pre-performance anxiety. Participants in the High Anxiety condition reported feeling more anxious before the math task $(M=5.73, S D=1.36)$ than did participants in the Low Anxiety condition $(M=5.21, S D=1.45), t$ $(186)=2.32, p=0.021, d=0.34$. In addition, participants in the High Anxiety condition answered fewer math questions correctly $(M=2.82$ out of $8, S D=1.74)$ than did participants in the Low Anxiety condition $(M=3.59, S D=1.73), t(186)=3.03, p=0.003$, $d=0.44$. There were no effects of age or gender on self-reported anxiety or math performance.

Subjective anxiety mediated the effect of task description on math performance. A 5000-sample bootstrap test estimated a standardized indirect effect of 0.31 ( $S E=0.038,95 \%$ biased-corrected $\mathrm{CI}$ $[0.09,0.26])$, indicating a significant indirect effect.

The results of this pilot study confirmed that the High Anxiety description of the math task induced pre-performance anxiety and harmed performance, with increases in anxiety linked to reduced performance.

\section{Study 2}

\subsection{Participants}

Because our pilot study included over 90 participants per experimental condition, we predetermined a sample size of 100 individuals per experimental condition. In total, we recruited 401 working adults on Amazon's Mechanical Turk ( $M_{\text {age }}=35.33$ years, $S D=10.55$ years, $45 \%$ female) to participate in a study in exchange for a $\$ 2$ show-up fee and the opportunity to earn up to $\$ 2$ bonus pay based on math performance. 


\subsection{Design}

We used a 2 (High Anxiety v. Low Anxiety) x 2 (Ritual v. No Ritual) factorial design. The dependent measure was performance on the math task used in the pilot study.

\subsection{Procedure}

All participants completed the same eight modular arithmetic problems under time pressure as in the pilot study (Beilock et al., 2004; Mattarella-Micke et al., 2011).

\subsubsection{Anxiety manipulation}

We manipulated the task description (High Anxiety v. Low Anxiety) using the instructions described in the pilot study.

\subsubsection{Ritual manipulation}

Before completing the math task, in the Ritual condition, we instructed participants to complete the same ritual as in Studies $1 \mathrm{a}$ and b. However, because participants completed this study online, the ritual steps were presented on the computer screen. In the No Ritual condition, we asked participants to "wait a few moments before starting the task." The instructions used in each of the conditions were displayed on the computer for ninety seconds.

\subsubsection{Math performance}

Our main dependent variable was math performance (number of correct answers out of eight questions). After participants completed the math task, they reported their demographics (age and gender). Finally, we paid participants the show-up fee (\$2) and $\$ 0.25$ for each question they solved correctly on the math task.

\subsection{Results}

\subsubsection{Preliminary analyses}

We observed significant effects of age and gender on math performance. Women performed worse than men $\left(M_{f e m}=3.31\right.$, $S D=1.52, \quad$ v. $M_{\text {male }}=3.67, \quad S D=1.59, \quad t(399)=2.34, \quad p=0.021$, $d=0.23$ ), and age was negatively correlated with performance $(r=-0.15, p=0.004)$. The main pattern of results was the same with or without including age and gender as control variables. We present our results collapsed across these variables.

\subsubsection{Math performance}

We conducted a 2 (High Anxiety v. Low Anxiety) $\times 2$ (Ritual v. No Ritual) ANOVA on performance on the math task (number of correct answers out of eight). We observed a significant main effect of ritual condition on math performance, $F(1,397)=4.34, p=0.038$, $\eta_{p}{ }^{2}=0.01$, such that participants who completed the ritual performed better on the math task $(M=3.66, S D=1.66)$ than did participants who did not complete the ritual $(M=3.35, S D=1.46)$.

The main effect of anxiety condition on math performance was consistent with the Math Task Pilot Study and marginally significant, $F(1,397)=2.74, p=0.099, \eta_{p}{ }^{2}=0.01$ : participants performed marginally worse on the math task in the High Anxiety condition $(M=3.39, S D=1.58)$ than in the Low Anxiety condition $(M=3.63$, $S D=1.55$ )

The interaction effect between the anxiety condition and the ritual condition on math performance did not reach significance, $F(1,397)=2.55, p=0.111, \eta_{p}{ }^{2}=0.01$. However, because our primary hypothesis was that the effect of ritual would be greatest in the High Anxiety condition, we conducted planned contrasts of the simple effects. The results supported our predictions: compared to math performance under conditions of Low Anxiety where the ritual had no effect $\left(M_{\text {ritual }}=3.67, S D=1.60\right.$,
$\left.M_{\text {noritual }}=3.59, S D=1.50, t(196)=0.35, p=0.731\right)$, under conditions of High Anxiety, the absence of a ritual harmed performance $\left(M_{\text {ritual }}=3.66, S D=1.71, M_{\text {noritual }}=3.08, S D=1.37, t(201)=2.61\right.$, $p=0.010, d=0.37)$. These results are consistent with our account that rituals can mitigate the detrimental effects of anxiety on performance. We depict these results in Fig. 2.

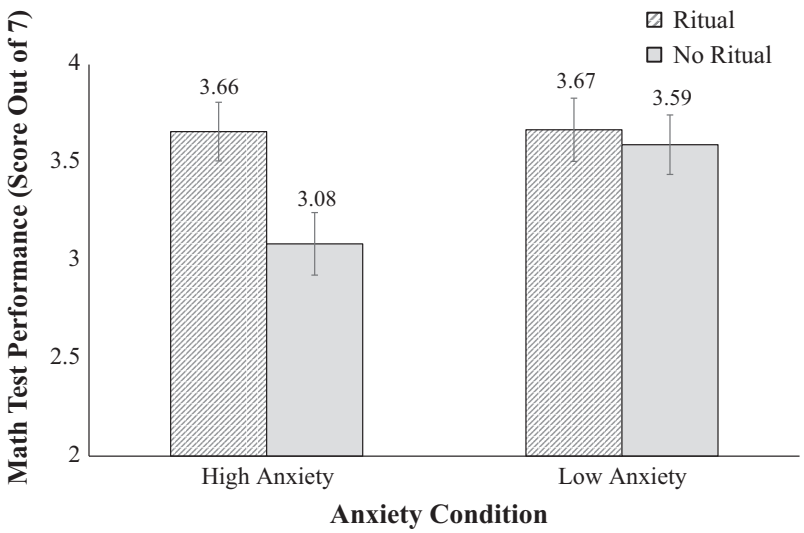

Fig. 2. Effect of ritual condition and anxiety on math performance (Study 2). Doing a ritual improved math test performance compared to not doing a ritual in the high anxiety condition. Error bars represent SEM.

\subsection{Discussion}

The results of Study 2 demonstrate that enacting a ritual can mitigate performance decrement on a high-anxiety math task, but does not influence performance on the same task under conditions of low anxiety. While rituals likely influence behavior due to a variety of psychological mechanisms, the mediation results from Study $1 \mathrm{a}$ and moderation results from Study 2 suggest that rituals' effects on anxiety reduction plays a critical role in driving the beneficial effect of rituals on performance.

\section{Study 3: "Ritual versus "Random Behaviors}

In our previous studies, enacting rituals reduced anxiety and improved performance in a public performance domain (singing) and a private performance domain (math). In addition to meeting our definition of a predefined sequence of symbolic actions characterized by formality and repetition that lacks direct instrumental purpose, our ritual manipulation in these studies included an affective element: "draw your feelings." Prior research suggests that expressing emotion itself can reduce negative emotion (Pennebaker, 1997). To more clearly test whether rituals themselves - rather than benefits arising from emotional expression decrease anxiety and improve performance, we use a different ritual in Study 3, replacing the "draw your feelings" step from the ritual used in our prior studies with a less emotional, more repetitive "count out loud slowly up to 10 from 0 , then back down to 0 " step.

In Study 3, we assess the importance of another critical element of our definition of rituals - that they are constituted of a predefined sequence of symbolic actions - by adding a new condition in which the same set of steps was described as a series of "random behaviors." We expected that enacting steps described as a "ritual" - thus imbuing them with symbolic meaning - would improve performance compared to doing no ritual, whereas completing those same steps described as "random behaviors" would not improve performance. 


\subsection{Participants}

We predetermined the maximum sample size our laboratory would support that would also provide adequate statistical power, aiming for 40 participants per experimental condition. In total, we recruited 120 adults $\left(M_{\text {age }}=32.58\right.$ years, $S D=12.50,61 \%$ male $)$ to participate in exchange for $\$ 4$ each.

\subsection{Design}

We randomly assigned participants to one of three experimental conditions: Ritual, Random Behaviors, or No Ritual.

\subsection{Procedure}

We informed participants they would learn a new math skill and take a short test. The experimenter read instructions to participants that we adopted from our Math Test Pilot Study to induce high anxiety (see Appendix A for full instructions).

\subsubsection{Ritual manipulation}

Participants were then randomly assigned to one of three between-subjects conditions: Ritual, Random Behaviors, or No Ritual. Participants completed the same set of gestures in the Ritual and Random Behavior conditions. Specifically, participants followed these instructions:

Please count out loud slowly up to 10 from 0 , then count back down to 0 . You should say each number out loud and write each number on the piece of paper in front of you as you say it. You may use the entire paper. Sprinkle salt on your paper. Crinkle up your paper. Throw your paper in the trash.

We manipulated the description of these gestures: in the Ritual condition, participants were informed: "Before you start the test, please complete a short ritual." In the Random Behaviors condition, participants were informed: "Before you start the test, please complete a few random behaviors that we are pretesting for other studies." To further distinguish between the Ritual and Random Behavior conditions, in the Ritual condition, the experimenter called each step "the next step in the ritual," whereas in the Random Behavior condition the experimenter called each step "the next behavior to pre-test." In the No Ritual condition, participants were informed: "Before you start the test, please wait for $30 \mathrm{~s}$ " to equate the timing of the math task across conditions.

\subsubsection{Math task}

Before starting the test, participants completed three example problems and three practice problems with the experimenter. For each of these problems, the experimenter corrected any missteps. All participants successfully solved the last practice problem correctly, demonstrating mastery over the novel task. Before starting the test, the experimenter turned on the video cameras and started the stopwatch, as he had explained. The test consisted of 14 modular arithmetic problems that used the same format as the problems in Study 2. When the participant was finished, the experimenter turned off the video cameras and stopped the stopwatch. ${ }^{3}$

\footnotetext{
${ }^{3}$ After the math task, participants in the Ritual condition reported the perceived effectiveness of the ritual $(1=$ Ritual harmed my performance; $9=$ Ritual helped my performance). If they reported that the ritual had helped their performance (rating above 5), we asked them how they thought the ritual had helped (multiple choice: Cleared my mind, Reduced anxiety, Brought good luck, Let me express my emotions). On average, participants believed the ritual had neither hindered nor helped their performance $(M=5.03, S D=0.59)$. Only two participants believed the ritual had helped (with a rating of above "5" on the response scale), and both of these participants thought the ritual reduced their anxiety.
}

10.4. Results

\subsubsection{Preliminary analyses}

We found no effect of gender or age on math performance, $t$ $(117)=-0.95, p=0.35 ; r=-0.09, p=0.34$, respectively. Females performed non-significantly worse than males $\left(M_{f e m}=9.11\right.$, $\left.S D=2.51 ; M_{\text {male }}=9.55, S D=2.43\right)$. We report our results collapsed across these variables.

\subsubsection{Math performance}

Math test performance differed by experimental condition, $F$ $(2,117)=2.99, p=0.05, \eta_{p}{ }^{2}=0.05$. As predicted, participants in the Ritual condition achieved the highest test score $(M=10.15$, $S D=2.55)$ : significantly higher than participants in the No Ritual condition $(M=8.90, S D=2.46), t(117)=2.31, p=0.022, d=0.50$ and marginally higher than participants in the Random Behaviors condition $(M=9.15, S D=2.36), t(117)=1.85, p=0.067, d=0.41$. Importantly, scores were not significantly different for participants in the Random Behaviors condition and the No Ritual condition, $t$ $(117)<1$, suggesting that performing the same steps as participants in the Ritual condition did not have an effect when those steps were not imbued with the symbolic meaning of a "ritual" (Fig. 3).

\subsection{Discussion}

Merely calling a set of gestures a "ritual" improved subsequent performance compared to not performing a ritual at all, whereas completing the same set of gestures described as "random behaviors" did not. These results suggest that minimal, symbolic framing of gestures can improve performance. That is, merely enacting a series of steps did not improve performance - only enacting a sequence of steps termed a ritual improved performance.

\section{Study 4: Rituals, anxiety, and control}

In Study 4, we again examined the effect of ritualistic behaviors that were framed either as a "ritual" or as "random behaviors" on an anxiety-inducing math test. In addition, this study also measured anxiety and another potential mechanism: perceived control. Study 2 suggested that rituals can mitigate poor performance when anxiety is high, offering support for a specific and critical role for anxiety in the effectiveness of rituals. However, anxiety is also characterized by low control (Smith \& Ellsworth, 1985). Therefore, it is possible that rituals may both decrease

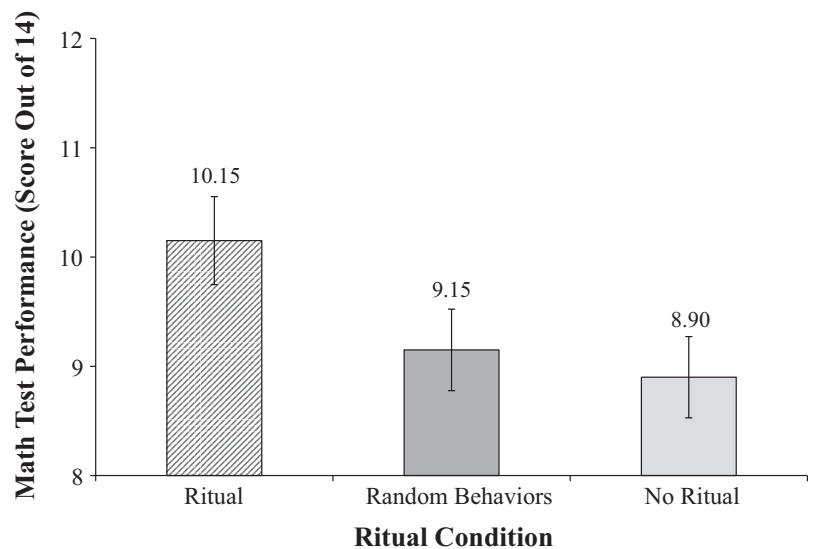

Fig. 3. Effect of ritual condition on math performance (Study 3). Math test performance was highest when individuals performed a ritual. Error bars represent SEM. 
anxiety and increase control. In Study 4, we assess both constructs as possible mediators, expecting to find further evidence for the critical role of anxiety reduction in the beneficial effects of rituals on performance.

\subsection{Participants}

We aimed to collect as many participants as possible in our laboratory over the course of one summer. We expected we would be able to recruit at least fifty participants per experimental condition and fell slightly short of this target. In total, 89 adults participated $\left(M_{\text {age }}=35.16\right.$ years, $S D=12.47$ years, $30 \%$ female, 5 participants missing demographic data) for $\$ 2$.

\subsection{Design}

We randomly assigned participants to either the Ritual condition $(N=44)$ or the Random Behaviors condition $(N=45)$.

\subsection{Procedure}

\subsubsection{Ritual manipulation}

We used the same procedure and experimental manipulation as in Study 3.

\subsubsection{Math task}

Following our manipulation calling the random behaviors a "ritual" or "random behaviors," participants completed the math task, following the same procedure as in Study 3.

\subsubsection{Anxiety and control measures}

After the math test, participants completed the 20-item state version of the state-trait anxiety inventory (STAI; Spielberger, Gorsuch, Lushene, Vagg, \& Jacobs, 1983) measured on a 4-point Likert scale. We used this extended measure to complement the abbreviated self-reported measure of anxiety we used in Studies $1 \mathrm{a}$ and 2 and the physiological measure of heart rate we used in Study 1b. Participants also completed a seven-item state measure of personal control (Pearlin \& Schooler, 1978), measured on a 7point Likert scale; these measures were counterbalanced. Finally, participants reported their age and gender.

\subsection{Results}

\subsubsection{Preliminary analyses}

We found no effect of gender or age on math performance, $t$ $(82)=0.99, p=0.324 ; r=0.05, p=0.650$, respectively. We collapsed across these variables in our analyses.

\subsubsection{Math performance}

Participants in the Ritual condition performed better on the math test than did participants in the Random Behaviors condition $\left(M_{\text {ritual }}=9.50, S D=2.45 ; M_{\text {random }}=8.38, S D=2.69\right), t(87)=2.05$, $p=0.043, d=0.44$.

\subsubsection{Anxiety}

Participants who completed the behaviors described as a "ritual" reported that they felt less anxious $(M=1.83, S D=0.56)$ than did participants who completed the same behaviors described as "random behaviors" $(M=2.07, S D=0.37), t(87)=2.39, \quad p=0.019$, $d=0.51$.

\subsubsection{Control}

We found no differences across ritual conditions in perceptions of control $\left(M_{\text {ritual }}=5.55, S D=1.13 ; M_{\text {random }}=5.56, S D=1.26\right), t(82)$ $=0.06, p=0.96$ (Fig. 4). ${ }^{4}$

\footnotetext{
4 The five participants who did not include their demographics also did not complete the control scale.
}

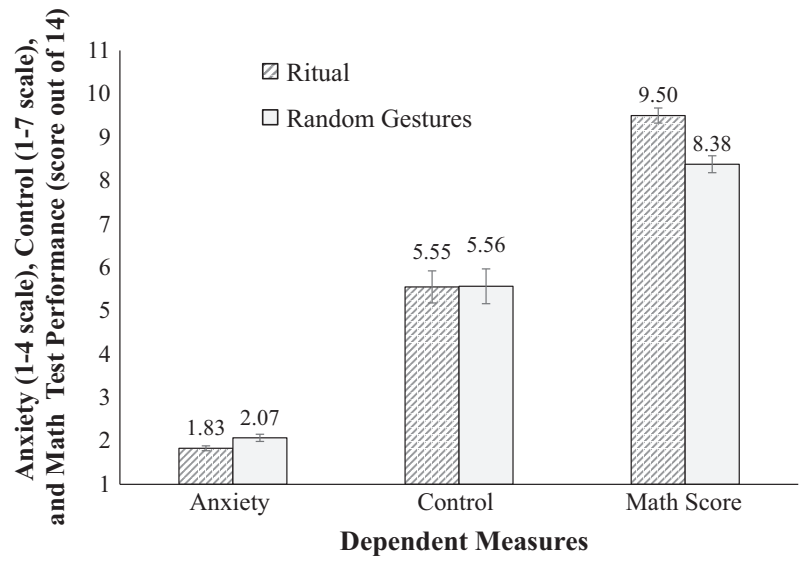

Fig. 4. Effect of ritual condition on anxiety, control, and math performance (Study 4). Participants reported lower anxiety and achieved higher math test scores, but felt the same perceived control, when they performed gestures described as a "ritual" instead of those described as "random." Errors bars represent SEM.

\subsubsection{Mediation}

We ran a 5,000 sample bootstrapped mediation model testing the effect of ritual condition on test performance, including both anxiety and control as mediators. The indirect effect of anxiety on test performance was significant, $95 \% \mathrm{CI}[0.02,0.77]$ but the indirect effect of control was not significant, 95\% CI [-0.22,0.25] (Fig. 5).

We also tested anxiety as a separate mediator. In a bootstrapped mediation model, anxiety mediated the path from ritual condition to test performance, consistent with our findings in prior experiments. But unlike prior experiments, the indirect effect was not significant, $95 \% \mathrm{CI}[-0.01,0.60]$. Finally, to be thorough, we also tested the reverse causal pathway to see if performance mediated the effect of ritual on anxiety. There was no indirect effect, 95\% CI $[-0.004,0.115]$.

\subsection{Discussion}

Replicating Study 3, enacting a set of steps described as a "ritual" boosted math performance compared to completing the same set of steps described as "random behaviors." Moreover, consistent with our earlier studies and our overall account, people reported less anxiety when behaviors were described as part of a ritual rather than as random behaviors. Our ritual manipulation did not affect feelings of perceived control, and feelings of perceived control were unrelated to math performance. Although we did not observe differences in perceived control between describing the behaviors as a "ritual" versus random behaviors, it is possible that perceived control is higher after engaging in rigid and repetitive behaviors - even when labeled "random" - compared to not engaging in any behaviors. Future research should investigate how rituals influence both anxiety and perceived control across different domains (see also Norton \& Gino, 2014; Sax, 2010).

\section{General discussion}

Across many domains, anxiety impairs performance (Bandura, 1997; Brooks, 2014; Brooks \& Schweitzer, 2011; Eysenck, 1992; Gino et al., 2012; Han et al., 2007; Raghunathan \& Pham, 1999), yet previous research has identified relatively few prescriptions for contending with anxiety. Across our studies, we used multiple performance tasks and different rituals to show that rituals consistently decreased anxiety, as assessed by both self-reported anxiety and a physiological measure of anxiety: heart rate. Moreover, this 


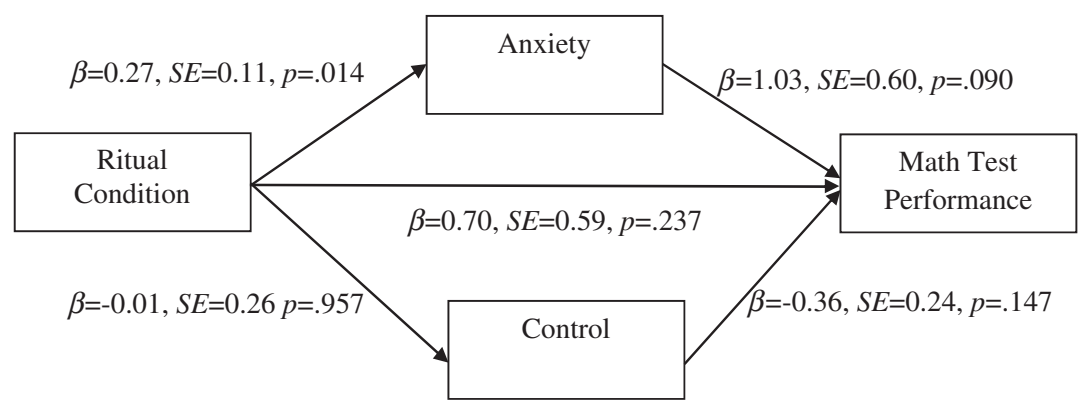

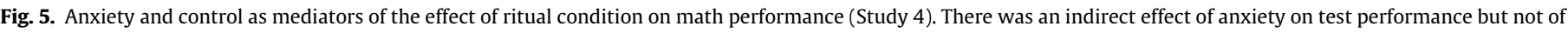
control.

reduction in anxiety improved performance - for both singing publicly and taking math tests alone. We tested the role of anxiety with mediation, moderation, by removing emotional expression from the ritual, and by comparing anxiety with another potential mechanism: perceived control. Across these approaches, decreased anxiety emerged as a unique and critical mechanism underlying the relationship between rituals and performance.

We conceptualized rituals as having three key elements (1) a pre-defined sequence characterized by rigidity, formality, and repetition that is (2) embedded in a larger system of symbolic meaning, and (3) lacking direct instrumental purpose. This conceptualization was supported by previous research and by our Pilot Study of people's real-life rituals. We designed novel rituals in our studies to align with this definition, and found that, across our studies, merely naming a set of behavioral steps a "ritual" was sufficient to harness the symbolic power of rituals on anxiety and performance.

\subsection{Theoretical contributions}

We make two primary theoretical contributions. First, our research adds to the literature exploring the effects of rituals on emotions and behavior. The present studies are the first to establish a causal link between rituals, anxiety, and performance. Enacting a ritual reduces anxiety in high-anxiety performance situations, which, in turn, can improve performance. Our findings also contribute to the literature on rituals by identifying an important link between rituals and symbolism. In Study 4, the effectiveness of rituals critically hinged on the presence or absence of a symbolic link between a set of behaviors enacted and the concept of a ritual. Through our experimental instructions, we imbued a set of steps with symbolic meaning by labeling them a "ritual," or removed that meaning by labeling them as "random behaviors." The critical element was not the series of steps but the fact that those steps were enacted as a ritual, suggesting that simply performing a sequence of pre-performance actions does not reduce anxiety or improve performance unless imbued with meaning. Our findings offer a deeper understanding of the relationship between rational and irrational (i.e., superstitious or magical) beliefs underlying ritualistic behavior. Prior work has found that rituals can help people feel better when they lack control (e.g., losing a loved one, Norton \& Gino, 2014). Our findings suggest that rituals can also make people feel better when facing a situation in which they objectively do have control. Moreover, we find that rituals can help people perform better: by reducing anxiety, performance improves.

Second, our research contributes to the clinical literatures on stress, trait anxiety, coping, and emotion regulation. In our studies, rituals reduced state anxiety, a feeling that many people experience in situations that arise over the course of a typical day. Our approach to studying state anxiety has broad application and advances prior research focused on rituals within the context of more stable trait anxiety or obsessive-compulsive disorder (e.g., Rachman \& Hodgson, 1980; Reuven-Magril et al., 2008). Whereas research on clinical populations has tended to focus on the downsides of overly ritualistic behavior - which can interfere with everyday life when too elaborate or repetitive - our results suggest that rituals enacted by non-clinical populations faced with performing can beneficially reduce anxiety. As a result, we demonstrate that rituals can serve an important, practical function. Our findings shed new light on prior research suggesting that superstitions and rituals are irrational (Jahoda, 2007; Sax, 2010). Despite their seeming irrationality, rituals can have a constructive influence on both the experience of state anxiety and subsequent performance.

Relatedly, our results contribute to the literature on emotion suppression and expression. Reducing anxious arousal immediately before and during anxiety-inducing tasks is difficult, and avoidance strategies, such as suppression, can paradoxically increase the experience of anxiety (Hofmann et al., 2009). We show that engaging in approach-related behaviors can be more effective than trying to suppress negative emotion when faced with performance situations: completing a ritual reduced anxiety and enhanced performance more than explicitly trying to calm down. Despite the frequency with which people experience performance anxiety, only a few other successful strategies have been documented, such as expressive writing (Pennebaker, 1997; Ramirez \& Beilock, 2011), reappraisal (Gross, 2002), cognitive behavioral therapy (Webb et al., 2012), and embodied actions (Li, Wei, \& Soman, 2010;). In contrast to these strategies, rituals are relatively easy to implement and align with conventional wisdom - many people use rituals naturally to cope with their anxiety.

\subsection{Future directions}

The current studies offer promising directions for future research. We have shown that enacting a ritual improves performance by decreasing anxiety, but a more fine-grained exploration of the relationship between ritual and state anxiety would be useful. As discussed in the Introduction, the rigidity and formality of ritualistic behaviors may help reduce anxiety in certain circumstances; the fact that the same set of behaviors was more effective for reducing anxiety when represented as a "ritual" than as "random behaviors," suggests that the symbolic meaning of ritual plays a critical role. We suggested that enacting a ritual with symbolic meaning may reduce anxiety by providing a broader perspective on the self or by acting like a placebo. In Study 3, we found that rituals were effective even though most participants did not believe the ritual would help their performance, suggesting that a placebo mechanism is unlikely to fully explain our results. Future research should explore the underpinnings of ritual effectiveness in greater detail. 
An exploration of additional mechanisms - beyond reducing anxiety - by which rituals improve performance is an additional promising direction. For example, rituals may increase intrinsic involvement in an upcoming task, similar to the way in which rituals increase involvement in consumption experiences (Vohs et al., 2013). Involvement and curiosity typically exert a positive effect on performance (Harzer \& Ruch, 2014; Reio \& Callahan, 2004), suggesting that rituals could improve performance by boosting involvement.

Our participants completed an externally-imposed, novel ritual. Methodologically, this allowed us to randomly assign rituals and measure their effects on emotion and behavior. However, future research should assess aspects of existing rituals to determine which elements may be more or less effective for reducing anxiety and improving performance. Indeed, our Pilot Study identified many aspects of rituals that warrant further examination. For example, most pre-performance rituals involve both cognitive and physical elements. Although we have shown that emotional expression is not essential for rituals to be effective (Studies 3 and 4), research is needed to assess when rituals are more effective for reducing anxiety and improving performance: do they require cognitive elements, physical elements, or both? Of course, the effectiveness of these elements likely also depends on the nature of the performance task. Future research might identify a matching effect - a cognitive ritual may be more effective in reducing anxiety about a cognitive task and a physical ritual may be more effective in reducing anxiety for a physical task.

Finally, the majority of participants in our Pilot study reported that they used their ritual before, but participants in our studies completed a ritual once. Future research should investigate whether a ritual that has been used before is more effective than a novel ritual, how people develop their own rituals in the face of anxiety, and how those rituals both solidify and change over time. We suspect that succeeding on a difficult task even a single time after a ritual may be sufficient to reinforce repeated ritualistic behavior over the longer term.

One particularly interesting direction may be to study group rituals. Although the majority of our participants reported that they performed rituals alone, pre-performance group rituals are common. Drew Brees, the quarterback of the New Orleans Saints, brings his team together before each game and engages them in a ritual chant (i.e., Drew: "One," Saints: "Two," Drew: "Win," Saints: "For you," Drew: "Three," Saints: "Four," Drew: "Win," Saints: "Some more!"). Similarly, many pop stars, such as Katy Perry and Miley Cyrus, bring stage performers and production staff together for a shared ritual pre-concert. Future research can explore team-based effects of performing rituals. Do rituals improve information exchange and physical coordination, and increase the flow of ideas? Group rituals may also offer other benefits in addition to performance, such as increasing liking and feelings of connection among group members.

\section{Conclusion}

We demonstrate that rituals improve performance. Simple, novel rituals reduce anxiety, lower elevated heart rates, and improve performance - provided they are imbued with symbolic meaning. In our Pilot Study, roughly half of participants reported engaging in pre-performance rituals; although some may dismiss rituals as irrational, those who enact rituals may well outperform the skeptics who forgo them.

\section{Acknowledgement}

We thank the Wharton Behavioral Laboratory, the Chicago Research Laboratory, and the University of Chicago Decision
Research Laboratory for their assistance with collecting the data reported in this paper. Correspondence concerning this article may be sent to either awbrooks@hbs.edu or jschroeder@berkeley. edu.

\section{Appendix A}

\section{Instructions read to participants by experimenter (Study 3):}

"Today we are testing your ability to learn a new type of math computation called modular arithmetic. Studies show that ability to solve modular arithmetic tasks is linked to your intelligence. It also predicts your GPA and has even been shown to predict future salary. I will explain to you how to solve a modular arithmetic task, and then I will give you 3 practice problems and I will explain the correct answer to you for each of these problems. Finally, you will take a test to see what you have learned. The test will consist of 14 problems. Your performance will be timed by the computer. There is a time limit for each problem. If you do not answer within the set time limit, the computer automatically moves to the next question and you get the problem wrong. I will put a stopwatch right here so that you can keep track of how much time you take per question. I'll start it just before you begin the test. This computer has a program that will calculate a Modular Arithmetic Score as you take the test. Your score will take into account both the time that you take to complete each question and whether or not you get the question correct. You will need to work as quickly and accurately as possible to maximize your score. Your pay for this study will be determined by your Modular Arithmetic Score on this test. The maximum amount of payment you can get is $\$ 4$, and the minimum amount is $\$ 0$. Finally, you will be videotaped by these two cameras as you take the test. We want to know how quickly you learn and how you perform, so researchers and educators at schools in [your city] will be viewing these videos in order to examine performance on math tasks. Please repeat back to me what you will be doing so I know you understand."

\section{References}

Ahler, J. G., \& Tamney, J. B. (1964). Some functions of religious ritual in a catastrophe. Sociology of Religion, 25(4), 212-230.

Anastasi, M. W., \& Newberg, A. B. (2008). A preliminary study of the acute effects of religious ritual on anxiety. The Journal of Alternative and Complementary Medicine, 14(2), 163-165.

Atran, S. \& Henrich. J. (2010). The evolution of religion: How cognitive by-products, adaptive learning heuristics, ritual displays, and group competition generate deep commitments to prosocial religions. Biological Theory, 5, 18-30.

Bandura, A. (1997). Self-efficacy: The exercise of control. New York: Freeman.

Beilock, S. (2008). Math performance in stressful situations. Current Directions in Psychological Science, 17, 339-343.

Beilock, S., \& Carr, T. H. (2005). When high-powered people fail-Working memory and "choking under pressure" in math. Psychological Science, 16, 101-105.

Beilock, S. L., Kulp, C. A., Holt, L. E., \& Carr, T. H. (2004). More on the fragility of performance: Choking under pressure in mathematical problem solving. Journal of Experimental Psychology: General, 133, 584-600.

Bell, C. (1997). Ritual: Perspectives and dimensions. Oxford, England: Oxford University Press.

Blagden, J. C., \& Craske, M. G. (1996). Effects of active and passive rumination and distraction: A pilot replication with anxious mood. Journal of Anxiety Disorders, $10,243-252$.

Blake, J. (2014). Identity on the march: Participating in contentious rituals in Northern Ireland. APSA 2014 annual meeting paper (Vol. 42).

Boyer, P., \& Liénard, P. (2006). Precaution systems and ritualized behavior: Behavioral and Brain Sciences, 29(06), 635-641.

Boyer, P., \& Liénard, P. (2008). Ritual behavior in obsessive and normal individuals moderating anxiety and reorganizing the flow of action. Current Directions in Psychological Science, 17, 291-294.

Brooks, A. W. (2014). Get excited: Reappraising pre-performance anxiety as excitement. Journal of Experimental Psychology: General, 143(3), 1144

Brooks, A. W., \& Schweitzer, M. E. (2011). Can Nervous Nelly negotiate? How anxiety causes negotiators to make low first offers, exit early, and earn less profit. Organizational Behavior and Human Decision Processes, 115, 43-54. 
Brunyé, T. T., Mahoney, C. R., Giles, G. E., Rapp, D. N., Taylor, H. A., \& Kanarek, R. B. (2013). Learning to relax: Evaluating four brief interventions for overcoming the negative emotions accompanying math anxiety. Learning and Individual Differences, 27, 1-7.

Celsi, R. L., Rose, R. L., \& Leigh, T. W. (1993). An exploration of high-risk leisure consumption through skydiving. Journal of Consumer Research, 1, 1-23.

Cohn, P. J. (1990). Preperformance routines in sport: Theoretical support and practical applications. The Sport Psychologist, 4, 301-312.

Cohn, P. J., Rotella, R. J., \& Lloyd, J. W. (1990). Effects of a cognitive-behavioral intervention on the preshot routine and performance in golf. The Sport Psychologist, 4, 33-47.

Collins, R. (2004). Interaction ritual chains. Princeton University Press.

Critcher, C. R., \& Dunning, D. (2014). Self-affirmations provide a broader perspective on self-threat. Personality and Social Psychology Bulletin, 41, 3-18.

Crum, A. J., \& Langer, E. J. (2007). Mind-set matters: Exercise and the placebo effect. Psychological Science, 18(2), 165-171.

Crum, A., Salovey, P., \& Achor, S. (2013). Rethinking stress: The role of mindsets in determining the stress response. Journal of Personality and Social Psychology, 104, 727.

Czech, D. R., Ploszay, A., \& Burke, K. L. (2004). An examination of the maintenance of preshot routines in basketball free throw shooting. Journal of Sport Behavior, 27, 323.

Damisch, L., Stoberock \& Mussweiler, T. (2010). Keep your fingers crossed! How superstition improves performance. Psychological Science, 21, 1014-1020.

Dunleavy, A. O., \& Miracle, A. W. Jr, (1979). Understanding ritual and its use in sport. Sport and the humanities: A collection of original essays. Knoxville, NT: The Bureau of Educational Research and Service, College of Education, The University of Tennessee.

Durkheim, E. (1912). The elementary forms of religious life. New York: Free Press.

Eysenck, M. W. (1992). Anxiety: The cognitive perspective. London: Erlbaum.

Eysenck, M. W. (1997). Anxiety and cognitive processes. In C. Cooper \& V. Varma (Eds.), Processes in individual differences. London: Routledge.

Felson, R. B., \& Gmelch, G. (1979). Uncertainty and the use of magic. Current Anthropology, 20, 587-589.

Foster, D. J., Weigand, D. A., \& Baines, D. (2006). The effect of removing superstitious behavior and introducing a pre-performance routine on basketball free-throw performance. Journal of Applied Sport Psychology, 18, 167-171.

Gayton, W. F., Cielinski, K. L., Francis-Keniston, W. J., \& Hearns, J. F. (1989). Effects of preshot routine on free-throw shooting. Perceptual and Motor Skills, 68, 317-318.

Gino, F., Brooks, A. W., \& Schweitzer, M. E. (2012). Anxiety, advice, and the ability to discern: Feeling anxious motivates individuals to seek and use advice. Journal of Personality and Social Psychology, 102, 497-517.

Gray, J. (1991). Fear, panic, and anxiety: What's in a name? Psychological Inquiry, 2, $77-78$.

Gross, J. J. (2002). Emotion regulation: Affective, cognitive, and social consequences. Psychophysiology, 39, 281-291.

Gross, J. J., \& Levenson, R. W. (1995). Emotion elicitation using films. Cognition $\mathcal{E}$ Emotion, 9, 87-108.

Han, S., Lerner, J. S., \& Keltner, D. (2007). Feelings and consumer decision making: The appraisal-tendency framework. Journal of Consumer Psychology, 17, $158-168$.

Harzer, C., \& Ruch, W. (2014). The role of character strengths for task performance, job dedication, interpersonal facilitation, and organizational support. Human Performance, 27, 183-205.

Hirsch, J. B., Mar, R. A., \& Peterson, J. B. (2012). Psychological entropy: A framework for understanding uncertainty-related anxiety. Psychological Review, 119, 304-320.

Hofmann, S. G., Heering, S., Sawyer, A., \& Asnaani, A. (2009). How to handle anxiety: The effects of reappraisal, acceptance, and suppression strategies on anxious arousal. Behaviour Research and Therapy, 47, 389-394.

Irons, W. (1996). Morality, religion, and human nature. In W. Mark Richardson \& Wesley Wildman (Eds.), Religion and science: History, method, dialogue (pp. 375-399). New York: Routledge, Inc.

Iyriboz, Y., Powers, S., Morrow, J., Ayers, D., \& Landry, G. (1991). Accuracy of pulse oximeters in estimating heart rate at rest and during exercise. British Journal of Sports Medicine, 25, 162-164.

Jacobs, J. L. (1989). The effects of ritual healing on female victims of abuse: A study of empowerment and transformation. Sociology of Religion, 50, 265-279.

Jahoda, G. (2007). Superstition and belief. The Psychologist, 20, 594-595.

Jamieson, J. P., Mendes, W. B., Blackstock, E., \& Schmader, T. (2010). Turning the knots in your stomach into bows: Reappraising arousal improves performance on the GRE. Journal of Experimental Social Psychology, 46, 208-212.

Kirschenbaum, D. S., Ordman, A. M., Tomarken, A. J., \& Holtzbauer, R. (1982). Effects of differential self-monitoring and level of mastery on sports performance: Brain power bowling. Cognitive Therapy and Research, 6, 335-341.

Knight, W. E., \& Rickard, N. S. (2001). Relaxing music prevents stress-induced increases in subjective anxiety, systolic blood pressure, and heart rate in healthy males and females. Journal of Music Therapy, 38, 254-272.

Lang, P. J., Greenwald, M. K., Bradley, M. M., \& Hamm, A. O. (1993). Looking at pictures: Affective, facial, visceral, and behavioral reactions. Psychophysiology, 30, 261-273.

Lang, M., Krátký, J., Shaver, J. H., Jerotijević, D., \& Xygalatas, D. (2015). Effects of anxiety on spontaneous ritualized behavior. Current Biology, 25, 1892-1897.

Lazarus, R. S. (1993). Coping theory and research: Past, present, and future. Psychosomatic Medicine, 55, 234-247.
Legare, C. H., \& Souza, A. L. (2012). Evaluating ritual efficacy: Evidence from the supernatural. Cognition, 124, 1-15.

Li, X., Wei, L., \& Soman, D. (2010). Sealing the emotions genie: The effects of physical enclosure on psychological closure. Psychological Science, 21, 1047-1050.

Lienard, P., \& Boyer, P. (2006). Whence collective rituals? A cultural selection model of ritualized behavior. American Anthropologist, 108, 814-827.

Lobmeyer, D. L., \& Wasserman, E. A. (1986). Preliminaries to free throw shooting: Superstitious behaviour? Journal of Sport and Behavior, 9, 70-78.

MacKinnon, D. P., Fairchild, A. J., \& Fritz, M. S. (2007). Mediation analysis. Annual Review of Psychology, 58, 593-614.

Malinowski, B. (1954). Magic, science and religion. Glencoe, IL: Free Press.

Mattarella-Micke, A., Mateo, J., Kozak, M. N., Foster, K., \& Beilock, S. L. (2011). Choke or thrive? The relation between salivary cortisol and math performance depends on individual differences in working memory and math-anxiety. Emotion, 11, 1000-1005.

McCann, P., Lavallee, D., \& Lavallee, R. (2001). The effect of pre-shot routines on golf wedge shot performance. European Journal of Sport Science, 1, 1-10.

Moore, W. E. (1986). Covert-overt service routines: The effects of a service routine training program on elite tennis players Unpublished doctoral dissertation. University of Virginia.

Norem, J. K., \& Chang, E. C. (2002). The positive psychology of negative thinking. Journal of Clinical Psychology, 58, 993-1001.

Norenzayan, A., \& Shariff, A. F. (2008). The origin and evolution of religious prosociality. Science, 322, 58-62.

Norton, M. I., \& Gino, F. (2014). Rituals alleviate grieving for loved ones, lovers, and lotteries. Journal of Experimental Psychology: General, 143, 266-272.

Orlick, T. (1986). Psyching for sport: Mental training for athletes. Champaign, IL: Leisure Press.

Ouellette, J. A., \& Wood, W. (1998). Habit and intention in everyday life: The multiple processes by which past behavior predicts future behavior. Psychological Bulletin, 124(1), 54.

Pearlin, L. I., \& Schooler, C. (1978). The structure of coping. Journal of Health and Social Behavior, 2-21.

Pennebaker, J. W. (1997). Writing about emotional experiences as a therapeutic process. Psychological Science, 8, 162-166

Predebon, J., \& Docker, S. B. (1992). Free-throw shooting performance as a function of preshot routines. Perceptual and Motor Skills, 75, 167-171.

Rachman, S., \& Hodgson, R. J. (1980). Obsessions and compulsions (p. 254) Englewood Cliffs, NJ: Prentice-Hall.

Radcliffe-Brown, A. R. (1939). Taboo: The Frazer lecture. Cambridge University Press.

Raghunathan, R., \& Pham, M. (1999). All negative moods are not equal: Motivational influences of anxiety and sadness on decision making. Organizational Behavior and Human Decision Processes, 79, 56-77.

Ramirez, G., \& Beilock, S. L. (2011). Writing about testing worries boosts exam performance in the classroom. Science, 331, 211-213.

Rappaport, R. A. (1999). Ritual and religion in the making of humanity. Cambridge University Press.

Reio, T. G., \& Callahan, J. L. (2004). Affect, curiosity, and socialization-related learning: A path analysis of antecedents to job performance. Journal of Business and Psychology, 19, 3-22.

Reuven-Magril, O., Dar, R., \& Liberman, N. (2008). Illusion of control and behavioral control attempts in obsessive-compulsive disorder. Journal of Abnormal Psychology, 117, 334.

Romanoff, B. D., \& Thompson, B. E. (2006). Meaning construction in palliative care: The use of narrative, ritual, and the expressive arts. The American Journal of Hospice \& Palliative Care, 23, 309-316.

Rossano, M. J. (2012). The essential role of ritual in the transmission and reinforcement of social norms. Psychological Bulletin, 138, 529-549.

Sax, W. S. (2010). Ritual and the problem of efficacy. In W. S. Sax, J. Quack, \& J Weinhold (Eds.), The problem of ritual efficacy (pp. 3-16). Oxford, UK: Oxford University Press.

Schmader, T., Johns, M., \& Forbes, C. (2008). An integrated process model of stereotype threat effects on performance. Psychological Review, 115, 336.

Shafir, R., Schwartz, N., Blechert, J., \& Sheppes, G. (2015). Emotional intensity influences pre-implementation and implementation of distraction and reappraisal. Social Cognitive and Affective Neuroscience, 10, 1329-1337.

Shearer, A., Hunt, M., Chowdhury, M., \& Nicol, L. (2015). Effects of a brief mindfulness meditation intervention on student stress and heart rate variability. International Journal of Stress Management, 23, 232-254.

Singer, B., \& Benassi, V. A. (1981). Occult beliefs: Media distortions, social uncertainty, and deficiencies of human reasoning seem to be at the basis of occult beliefs. American Scientist, 69, 49-55.

Smith, J. C., Bradley, M. M., \& Lang, P. J. (2005). State anxiety and affective physiology: Effects of sustained exposure to affective pictures. Biological Psychology, 69, 247-260.

Smith, C., \& Ellsworth, P. (1985). Patterns of cognitive appraisal in emotion. Journal of Personality and Social Psychology, 48, 813-838.

Spencer, S. J., Zanna, M., \& Fong, G. T. (2005). Establishing a causal chain: Why experiments are often more effective than mediational analyses in examining psychological processes. Journal of Personality and Social Psychology, 89, 845-851.

Spielberger, C. D., Gorsuch, R. L., Lushene, R., Vagg, P. R., \& Jacobs, G. A. (1983). Manual for the state-trait anxiety inventory. Palo Alto, CA: Consulting Psychologists Press.

Steele, C. M., \& Josephs, R. A. (1988). Drinking your troubles away II: An attentionallocation model of alcohol's effect on psychological stress. Journal of Abnormal Psychology, 97, 196-205. 
Tambiah, S. J. (1979). A performative approach to ritual. Proceedings of the British Academy, 45, 113-169.

Tinbergen, N. (1952). "Derived" activities: Their causation, biological significance, origin, and emancipation during evolution. Quarterly Biological Review, 27, 1-32.

Todd, A. R. Forstmann, M., Burgmer, P., Brooks, A. W., \& Galinsky, A. (2015). Anxious and egocentric: How specific emotions influence perspective taking. Journal of Experimental Psychology: General, 144, 374-391.

Van Dillen, L. F., \& Koole, S. L. (2007). Clearing the mind: A working memory model of distraction from negative mood. Emotion, 7, 715-723.

Vohs, K. D., Wang, Y., Gino, F., \& Norton, M. I. (2013). Rituals enhance consumption. Psychological Science, 24, 1714-1721.

Vyse, S. A. (1997). Believing in magic: The psychology of superstition. New York: Oxford University Press.
Webb, T. L., Miles, E., \& Sheeran, P. (2012). Dealing with feeling: A meta-analysis of the effectiveness of strategies derived from the process model of emotion regulation. Psychological Bulletin, 138, 775.

Whitson, J. A., \& Galinsky, A. D. (2008). Lacking control increases illusory pattern perception. Science, 322, 115-117.

Williams, R. P., Delizonna, L. L., \& Langer, E. J. (2009). The effect of mindfulness on heart rate control. Journal of Adult Development, 16, 61-65.

Womack, M. (1992). Why athletes need ritual: A study of magic among professional athletes. Sport and Religion, 191-202.

Wrisberg, C. A., \& Pein, R. L. (1992). The preshot interval and free throw shooting accuracy: An exploratory investigation. The Sport Psychologist, 6, 14-23.

Zhang, Y., Risen, J. L., \& Hosey, C. (2014). Reversing one’s fortune by pushing away bad luck. Journal of Experimental Psychology: General, 143, 1171-1184. 